REVISTA DE DERECHO UNED, NÚM. 24, 2019

\title{
EL PRINCIPIO DE IGUALDAD \\ EN LOS 30 AÑOS DE HISTORIA DE LA MUJER EN LAS FUERZAS ARMADAS
}

\section{EQUALITY PRINCIPLE IN THE 30 YEARS OF WOMEN'S HISTORY IN THE ARMED FORCES}

\section{JaVier De la Fuente Fernández}

Teniente de la Guardia Civil. Doctorando en el Programa de Unión Europea por la Universidad Nacional de Educación a Distancia (UNED)

Resumen: La incorporación de la mujer en las Fuerzas Armadas españolas ha sido uno de los acontecimientos más relevantes que se han dado en la historia del país. Esto ha originado un desarrollo normativo al objeto de regular la situación del personal femenino en estas unidades ya que, hasta hace treinta años, esta profesión era realizada únicamente por hombres. La sucesión de leyes ha facilitado la incorporación de un gran número de mujeres. Todo se ha desarrollado al objeto de alcanzar una igualdad efectiva. Esto ha permitido que, España se sitúe como un país referente en la OTAN en este contexto.

Palabras clave: Fuerzas Armadas, igualdad, incorporación, militar, mujer.

Abstract: The integration of women in the Spanish Armed Forces has been one of the most important events that have taken place in our recent history. This has led to the legal development of the professional status of women in these units, run only by men until thirty years ago. The succession of laws has facilitated the incorporation of a large number of women. Everything has been developed in order to achieve effective equality. This has allowed Spain to be a reference country in NATO. 
Keywords: Armed forces, equality, integration, military, women.

Recepción original: 04/02/2019

Aceptación original: 03/05/2019

Sumario: I. Introducción. II. Evolución normativa. III. Análisis estadístico. IV. Conclusiones.

\section{INTRODUCCIÓN}

La incorporación de la mujer a las Fuerzas Armadas (FAS) marcó un hito histórico en la vida profesional de este tipo de Unidades, consiguiendo desarrollar y mejorar, muchas de las actividades diarias.

La finalidad del texto, es dar a conocer la evolución histórica de la regulación legal que se ha ido promulgando en materia de igualdad, desde la incorporación de efectivos femeninos a las FAS, hasta la actualidad. Para ello, se realizará un análisis histórico-jurídico de la normativa generada, acompañada de una valoración estadística de las cifras de sus efectivos.

¿Por qué el principio de igualdad como tema principal del texto? El derecho de igualdad ha marcado un «antes y un después» en la esfera profesional de la mujer. Desde la segunda mitad del siglo pasado, se han originado una serie de normas ${ }^{1}$ que han permitido paulatinamente la obtención de más oportunidades en la vida laboral.

${ }^{1}$ En el último siglo, a nivel internacional, dentro de las primeras manifestaciones de la igualdad de género, se puede encontrar la normativa de la ONU, en la Carta de NNUU (1945), en la cita "...reafirmar la fe en los derechos fundamentales del hombre, en la dignidad y el valor de la persona humana, en la igualdad de derechos de hombres y mujeres...». Además, en la Declaración Universal de Derechos Humanos (1948) también se establece en su preámbulo el mismo principio de igualdad citando que, "...los pueblos de las Naciones Unidas han reafirmado en la Carta su fe en los derechos fundamentales del hombre, en la dignidad y el valor de la persona humana y en la igualdad de derechos de hombres y mujeres, $y$ se han declarado resueltos a promover el progreso social...»Posteriormente se han ido celebrando diferentes convenciones, pactos y normativa diversa que redundaban más en la igualdad y tenían como objetivo eliminar cualquier tipo de discriminación posible entre el hombre y la mujer. Entre otros se puede citar la Convención sobre los Derechos Políticos de la Mujer (1952) que promovió la ONU, los Pactos Internacionales de Derechos Económicos, Sociales y Culturales y de Derechos Civiles y Políticos (1966), la Carta de Derechos de las Mujeres (1979), la IV Conferencia Mundial sobre las Mujeres (1995), donde se estableció que los derechos de las mujeres son derechos humanos y, el Tratado de Ámsterdam. 
Todo ello es debido a la repercusión directa de este principio sobre el trabajador.

Una pregunta que se debe hacer el lector antes de continuar leyendo el texto es, ¿todas las normas que se han consagrado en las diferentes leyes del Estado, se ponen de manifiesto en el día a día de las personas? Es decir, ¿la igualdad formal es la misma que la igualdad real?2.

Al igual que en otros organismos $y$, en otras Unidades policiales y militares del país, se ha dejado claro el establecimiento en la Ley de principios que consagran la igualdad y no discriminación. Pese a todo ello, por mucho que se imponga en una norma estos principios, si no se lleva a la práctica, no habrá una igualdad efectiva. No se podrá dejar de lado este principio o derecho, ya que marca el camino o evolución de la mujer en su vida militar. Éste romperá con muchos estereotipos y barreras que se presentaban en el largo camino ${ }^{3}$ hasta la igualdad efectiva entre ambos sexos.

Al ser una temática bastante amplia y compleja, se referencia las principales normas que han ido aportando cambios significativos en la vida profesional de la mujer, a efectos de tener una idea global de los pasos que se han producido para alcanzar una integración plena.

\section{EVOLUCIÓN NORMATIVA}

La integración de la mujer en las FAS es relativamente reciente, al igual que en el resto de cuerpos policiales y militares que se en-

2 Antes de entrar en detalle y de forma general, hay que conocer la principal característica que los diferencia. La primera de ellas se refiere a que la ley debe tratar a todos por igual, sin hacer diferencia entre hombres y mujeres y, sin que la misma favorezca a un grupo u a otro, considerándose un derecho subjetivo para todos los ciudadanos. Por otro lado, la igualdad real, consistiría en una igualdad referente a la aplicación de la norma, es decir, todos los procedimientos de aplicación de la misma se realizarían en las mismas condiciones. Aun siendo definiciones diferentes del concepto de igualdad, ambas deben complementarse para una correcta aplicación de la ley e ir en el mismo camino para conseguir el objetivo marcado.

${ }^{3}$ El lector puede preguntarse el por qué la mujer no ha ingresado antes; la razón no era el que tuviera unas características peores que el hombre, o que no valiese para desempeñar este tipo de trabajos. A priori, se puede motivar esa tardanza, a la ideología del momento o, se puede pensar que las necesidades por entonces no las requerían. Con el análisis de todo lo que se expone a continuación, se puede interpretar y dar una respuesta más fundamentada a la pregunta. 
cuentran en España ${ }^{4}$. Como en todos ellos, la incorporación del personal femenino supuso un hito histórico, generando una adaptación a las nuevas circunstancias.

¿Por qué una adaptación? Esta integración supuso un nuevo marco normativo donde poder regular los nuevos cambios generados tales como vestuario, régimen disciplinario, régimen de personal, cuestiones varias como ascensos, destinos, etc. A pesar de todos estos cambios, el mayor logro sería cambiar la mentalidad de la población y así, cambiar los estereotipos creados ${ }^{5}$.

Hay que destacar que, de forma previa al ingreso de las mujeres en las FAS, existió un cuerpo femenino vinculado ${ }^{6}$ al ejército. Éste es conocido por el Cuerpo de Damas de Sanidad Militar, creado en el

${ }^{4}$ Dentro del ámbito europeo, la incorporación de la mujer a los diferentes ejércitos es dispar. Conforme a lo citado por Beatriz García Sánchez, se conoce que: "(...) en algunos de ellos, como el holandés, servían desde 1944 con las mismas reglas y las mismas exigencias disciplinarias que los hombres (...)». "En Francia las mujeres podían acceder a todos los empleos militares desde 1972, bajo el mismo régimen que los varones aunque en cuerpos femeninos específicos (...). En Alemania la participación de la mujer en sus ejércitos se remonta a 1977, aunque al principio solo en unos pocos puestos, al igual que ocurría en Suiza, donde también se aceptaron mujeres desde 1977. Mención aparte merece el caso de Gran Bretaña, donde nunca dejaron de formar parte de las Fuerzas Armadas desde que empezara a contarse con ellas a principios del siglo XX en cuerpos femeninos como los Women's Army Auxiliary (...). En Italia pero no sería hasta 1999 cuando se establecería el servicio militar voluntario femenino, lo que permitiría a las primeras italianas que así lo desearan entrar en las academias militares (...)» (Vid., GARCÍA SÁNCHEZ, B., "Integración real e instrumentalización de la imagen de la mujer en las Fuerzas Armadas españolas», Journal of feminist, gender and women studies, 2016, pág. 24). En el caso de Noruega, pese a que en el año 1942 se estableció el servicio militar obligatorio, éste fue suprimido en el 1957. Veinte años después, se estableció un sistema de cuotas para favorecer el acceso de mujeres a puestos que no fueran de combate y en 1985, se aprobó la incorporación de las mujeres sin discriminación alguna. Como se ha visto, en la década de los años ochenta se consolidan la integración de la mujer en muchos de los ejércitos europeos. Dejando a un lado este continente, "cabe destacar que EEUU ha sido el país pionero en la propuesta de medidas para la integración de las mujeres en las Fuerzas Armadas» (Vid., AGUDO ARROYO, Y., "La participación de las mujeres en las Fuerzas Armadas españolas: de la incorporación a la integración», Revista Internacional de Trabajo Social y Ciencias Sociales, 2014, pág. 17).

5 «Cambiar las infraestructuras y las leyes es más sencillo que el cambio de mentalidades. Todavía hay compañeros y superiores que no son favorables a la presencia de mujeres en los ejércitos» (Vid., AGUDO ARROYO, Y., "La participación de las mujeres en las Fuerzas Armadas españolas: de la incorporación a la integración», Revista Internacional de Trabajo Social y Ciencias Sociales, 2014, pág. 23).

6 A pesar de ello, En España, ya durante el gobierno del general Franco, se prohibía explícitamente el acceso de la mujer al Ejército; esto se ve en la Ley de 22 de julio de 1961 sobre derechos políticos, profesionales y laborales de la mujer. 
año 1941 mediante la Orden de 31 de julio de 19417, considerándose el primer contacto profesional de la mujer en este tipo de trabajos. A pesar de ello, autores como José Miguel Quesada, se remontan al año 1880 , para hablar de las primeras enfermeras con vinculación a la milicia ${ }^{8}$.

Al igual que narra Pilar Gallardo en su artículo, "los antecedentes de este Cuerpo están en la Guerra Civil, con las aspirantes de Cruz Roja Española, Sección Femenina de Falange y las que trabajaban en hospitales militares de forma voluntaria y sin titulación, llegándose a alcanzar el número de 12.307 enfermeras y auxiliares al finalizar la guerra».

Exceptuando el periodo de la Guerra Civil, el personal femenino incorporado en el Cuerpo de Damas de Sanidad, han sido las primeras mujeres que se vincularon al Ejército, con un gran espíritu de servicio y de forma totalmente desinteresada y altruista. Se considera fundadora del Cuerpo de Damas de Sanidad Militar a D. ${ }^{a}$ Mercedes Milá Nolla, que ocupó el cargo de Inspectora General.

${ }^{7}$ El primer reglamento fue aprobado por Orden de 31 de julio de 1941, por la que se publica el Reglamento del Servicio de Damas Auxiliares de Sanidad Militar (Diario Oficial del Ministerio del Ejército. n. ${ }^{\circ}$ 172/5 de agosto de 1941).

${ }^{8}$ Para conocer un poco la historia de las primeras mujeres que prestaron servicio a los ejércitos, hay que remontarse a finales del siglo XIX. Sin profundizar en esta cuestión, se citará lo más relevante acontecido sobre ellas. En 1880, el Ministerio de Guerra estableció un Cuerpo de enfermeras militares, conocidas por las Hijas de la Caridad de San Vicente de Paúl (considerándose uno de las primeras agrupaciones de sanidad), llevando a cabo actividades de cocina, lavandería, asistencia a pacientes, etc. dentro de los hospitales castrenses. De forma complementaría, la Cruz Roja española prestaría asistencia médica en zonas de conflicto. En 1899, ésta quedó formalmente vinculada a la Sanidad Militar, con dependencia del Ministerio de la Guerra y del Ministerio de Marina. "(...) la participación de la mujer española en la defensa se realizaba por medio del voluntariado civil y con estricta limitación al ámbito sanitario, ya fuera como dama seglar de la Cruz Roja, ya fuera como monja de la Caridad» (Vid., QUESADA GONZÁLEZ, J.M., «Las señoritas de la Cruz de Malta: una visión objetiva sobre las Damas Auxiliares de Sanidad Militar», Revista de historia militar n. ${ }^{\circ} 119,2016$, pág. 221). De forma paralela, se irían creando en diferentes países de Occidente, Cuerpos de enfermeras y auxiliares femeninos. En el caso de España, dentro del personal femenino que realizaría actividades sanitarias y con funciones de auxiliar, se situaría personal de la Cruz Roja y/ o monjas. Durante la Guerra Civil española, sirvieron tanto en la zona nacional, como en el republicano y, a su vez, realizaron importantes campañas en la División Azul. Una de las personas más influyentes de la época y que destacó por sus logros, fue D. ${ }^{a}$ Mercedes Milá Nolla, veterana de la Cruz Roja. Ésta, con cargo de inspectora general, lucharía por constituir un cuerpo con carácter militar.

9 Vid., GALLARDO RODRÍGUEZ, P., La mujer militar en las Fuerzas Armadas, en El papel de la mujer y el género en los conflictos. Cuadernos de Estrategia n. ${ }^{\circ}$ 157, Instituto español de Estudios Estratégicos, Granada, 2012, pág. 161.

(C) UNED. Revista de Derecho UNED, núm. 24, 2019 
Ya a mediados del siglo pasado se impartía una instrucción militar ${ }^{10},{ }^{11}$ a aquellas mujeres que, junto a conocimientos sanitarios, querían formar parte del Cuerpo de Enfermeras ${ }^{12}$; éste último, es una Unidad considerada de naturaleza civil ${ }^{13}$.

En el año 1977, se llevaría a cabo la división del Cuerpo de Damas ${ }^{14}$ de Sanidad militar, estableciéndose dos Cuerpos. Por un

10 Se referencia en el libro de Jerónimo González Yanes, Doctor en Historia Contemporánea, que "(...) la condición que se exigía para ingresar en este Cuerpo era la realización de un curso de dos años de duración, en el cual se adquirían una sería de conocimientos militares y de enfermería: instrucción en orden cerrado, técnicas clínicas, enfermería auxiliar y muchas prácticas hospitalarias(...) las tareas que desarrollaban en sus diferentes campos de actuación, principalmente, destacaban labores asistenciales en los diferentes hospitales militares, campañas de captación de donaciones de sangre en acuartelamientos o centros de instrucción de reclutas, auxiliar al personal sanitario durante maniobras y ejercicios tácticos; expediciones a colonias infantiles durante los meses de verano (...)» (Vid., GONZÁLEZ YANES, J. Historia de la enfermería en la Defensa. Ejército de Tierra: regulación normativa y marco jurídico de funciones profesionales, Tenerife, 2014,pág. 107).

11 Hasta la integración de la mujer en las Fuerzas Armadas, éstas han ido ocupando exclusivamente, puestos de trabajo en sanidad, auxiliar e industria. Como se cita en la Revista de Historia Militar n. ${ }^{\circ} 119$, «la presencia femenina en los escenarios de los conflictos fue puntual, (...) algunos ejércitos occidentales comenzaron a crear, por un lado, cuerpos compuestos por mujeres en exclusiva y, por otro, servicios en los que se admitía a mujeres y a hombres de forma indistinta. Entre los primeros se encuentran los de enfermeras, como el británico Army Nursing Service, que fue constituido en (...) y los auxiliares femeninos, destinados a atender centralitas telefónicas, al control aéreo, a cocinar, a realizar tareas administrativas o a servir bebidas en las cantinas, entre otros, por ejemplo, el Women's Army Corps, creado tras la entrada de Estados Unidos en la Segunda Guerra Mundial (...)Solo algunos países de la Europa Oriental (Rusia, por ejemplo) permitieron que cubrieran destinos operativos durante las dos guerras mundiales» (Vid., QUESADA GONZÁLEZ, J.M., "Las señoritas de la Cruz de Malta: una visión objetiva sobre las Damas Auxiliares de Sanidad Militar», Revista de historia militar n. ${ }^{\circ} 119,2016$, pág. 220).

12 Real decreto 2808/77, de 29 de setiembre, por el que se aprueba el reglamento del Cuerpo Especial de Damas Auxiliares de Sanidad Militar, publicado en el núm. 272, de 14 de noviembre de 1977, páginas 24798 a 24798 (1 pág. ).

13 "En cualquier caso, aunque vistiesen de uniforme, las Damas no fueron un cuerpo militar en tiempo de paz, ni tampoco lo hubiesen sido en caso de guerra. Eso impide que puedan ser consideradas una reserva militar. No obstante lo anterior, si que fueron una capacidad suplementaria significativa que habría podido ser de utilidad, de la misma manera que sucedió en otros países con colectivos similares» (Vid., QUESADA GONZÁLEZ, J.M., "Las señoritas de la Cruz de Malta: una visión objetiva sobre las Damas Auxiliares de Sanidad Militar», Revista de historia militar n. ${ }^{\circ} 119,2016$, pág. 241).

${ }^{14}$ "En 1974, por una Orden Ministerial del año 1.974 (B.O.E. N. ${ }^{\circ} 180$ de 29 de Julio de 1.974) se concedió al colectivo de Damas de Sanidad Militar el título de Técnico Auxiliar de Clínica, Formación Profesional, grado I, de la rama Sanitaria (titulación que deberían solicitar las interesadas de forma individual) y las del 
lado, estaría el Cuerpo especial de Damas Auxiliares de Sanidad Militar (considerándose funcionarias) y, la Agrupación de Damas Auxiliares de Sanidad Militar (realizarían un trabajo de carácter altruista). Posteriormente, la Sanidad Militar fue unificada por la aplicación de la Ley 27/1.989 como Cuerpo Común de la Defensa en 1.990 y tuvo que adaptarse a las modificaciones de esta nueva etapa $^{15}$.

Durante esta época, existieron diferentes problemas que llevarían al fin del Cuerpo Especial de Damas: uno de éstos, fue su carácter civil. Además, coincide con la celebración de la última convocatoria para el ingreso al Cuerpo (coincidiendo con la primera promoción de mujeres de las FAS). Muchas de las Damas quisieron convalidar sus titulaciones para entrar en las FAS y no pudieron. Asimismo, no había una normativa que regulase su situación actual, etc. Todo ello provocó que, en palabras de José Miguel Quesada ${ }^{16}$, «unos meses después de la promulgación del reglamento de reservistas voluntarios de 2003, el Cuerpo Especial de Damas Auxiliares de Sanidad Militar fue declarado a extinguir» ${ }^{17,18}$. Actualmente, la especialidad de enfermería queda integrada dentro de los Cuerpos Comunes de las Fuerzas Armadas.

Habiéndose conocido de forma puntual, los inicios de la mujer en la profesión militar, se pasa a desarrollar las principales leyes establecidas hasta la fecha actual. Como se irá viendo, desde antes

Cuerpo Especial fueron consideradas como funcionarias civiles de la Administración militar, según decreto 707/1976, de 5 de Marzo»[Vid., "Las otras enfermeras, durante la Guerra Civil.

https://www.researchgate.net/publication/292983004_PARANINFO_DIGITAL_ Las_otras_enfermeras_durante_la_Guerra_Civil_Espanola (último acceso: 8 de diciembre de 2018)].

${ }^{15}$ Vid., «Las Damas del Ejército: Sanidad Militar (I)». http://forodeculturadedefensa.blogspot.com/2013/04/las-damas-del-ejercito-sanidad-militar-i.html (último acceso: 6 de diciembre de 2018).

${ }^{16}$ José Miguel Quesada es Doctor en Paz y Seguridad Internacional por el Instituto Universitario General Gutiérrez Mellado (UNED).

17 Por medio de la Ley 62/2003, de 30 de diciembre, de medidas fiscales, administrativas y del orden social, se declara a extinguir el Cuerpo de Damas de Sanidad Militar. No obstante, antes de la declaración de su extinción, se promulgaría el Real Decreto 1691/2003, de 12 de diciembre, por el que se aprueba el primer Reglamento de Acceso y Régimen de los Reservistas Voluntarios que confirma en su Disposición adicional única la integración de las Damas auxiliares de Sanidad Militar como reservistas voluntarios.

18 Vid., QUESADA GONZÁLEZ, J.M., "Las señoritas de la Cruz de Malta: una visión objetiva sobre las Damas Auxiliares de Sanidad Militar», Revista de historia militar n. ${ }^{\circ} 119,2016$, pág. 237. 
de su incorporación, la mujer ya tenía barreras ${ }^{19}$ para poder formar parte de los ejércitos. Una vez integrada, se le seguían presentando obstáculos normativos, donde, por ejemplo, le impedían formar parte de determinadas Unidades de combate. Como se verá posteriormente en el texto, "en España, actualmente no hay limitaciones formales» ${ }^{20}$.

Son varias las leyes que dan pie a que la mujer española pudiese formar parte de los ejércitos del país, así como otras tantas cuyo origen se basa en la adaptación de esa nueva incorporación. Uno de los pilares fundamentales, se puede encontrar en la Constitución Española de 1978 (CE). La CE consagra en sus artículos 9.2 y 14, el derecho a la igualdad entre hombres y mujeres, principio que debe manifestarse sin discriminación en todas las esferas de la vida y ha servido de base en la sucesión de leyes. Como se ha reflejado, se parte de una base legal teórica, referente a la igualdad formal, que deberá ir evolucionando hasta consagrarse en la esfera real de todo ciudadano ${ }^{21}$.

19 Según Víctor Martín, los frentes que se le han presentado y que han retrasado su incorporación, se pueden agrupar en cuatro grandes grupos: "1. Tradición; es obvio que, durante siglos, la institución militar ha sido, como muchos otros, un ámbito expresamente vedado a la mujer. Por tanto, y con el paso de los siglos, ello ha llevado a concebir la profesión militar como una ocupación típicamente masculina, estereotipo que aún hoy perdura en cierta medida (...). 2. Menos capacidad física; este es, aún hoy, uno de los argumentos más utilizados para oponerse, al menos parcialmente, a la entrada de mujeres a la milicia. Que la capacidad de trabajo físico de las mujeres es, por norma general, ligeramente inferior a las de los hombres en algunas áreas (fuerza y velocidad, principalmente) es un hecho sobre el que se ha apoyado el argumento anterior (...). 3. Cuestiones biológicas y fisiológicas, que toman en consideración, por ejemplo, desde la densidad ósea del esqueleto femenino a la posible influencia de la menstruación en el rendimiento y concentración. Normalmente, este tipo de consideraciones van encaminadas a cuestionar (...) la aptitud de la mujer para el desempeño de determinados puestos de primera linea (pilotos de combate, submarinistas, tropas de asalto, etc.) . 4. Cuestiones tácticas ; (...) pérdida de moral y disfunción operativa que causan las bajas femeninas, o la resistencia de combatientes de ciertas culturas a rendirse ante un soldado, prefiriendo luchar hasta la muerte antes que ser hechos prisioneros por una mujer» [Vid., MARTÍN MARTÍNEZ, V., "La incorporación de la mujer a las Fuerzas Armadas», en Las mujeres militares en España (1988-2008), de María Gómez Escarda y Isidro Sepúlveda Muñoz, Instituto Universitario General Gutiérrez Mellado, Madrid, 2009, pág. 32].

${ }^{20} \mathrm{Vid}$., AGUDO ARROYO, Y., «La participación de las mujeres en las Fuerzas Armadas españolas: de la incorporación a la integración», Revista Internacional de Trabajo Social y Ciencias Sociales, 2014, pág. 18.

21 Asimismo, lo expresa María Belén Caballud diciendo: "Podemos hablar, por tanto, de un modelo español de incorporación de la mujer, un modelo que está caracterizado por la consecución, en un primer momento, de la igualdad legal para evolucionar, una vez conseguida ésta, hacía la igualdad efectiva y real de los miembros de las Fuerzas Armadas españolas» [Vid., CABALLUD HERNANDO, M.B., "Aportación de la mujer militar en las Fuerzas Armadas españolas a la defensa y la seguridad» en 
Legalmente, se podría pensar que la tardía ${ }^{22}$ incorporación de la mujer a los ejércitos, podría contradecir alguno de los artículos mencionados de la CE y, en especial, el propio artículo 30.1 que establece que: "Los españoles tienen el derecho y el deber de defender a España», no haciendo distinción alguna entre hombres y mujeres.

En palabras de Francisco Fernández Segado, Catedrático de Derecho Constitucional, "la entrada en vigor de la Constitución de 1978 convertía en ineludible la reforma de la ya añeja Ley 55/1968, de 27 de julio, General del Servicio Militar» ${ }^{23},{ }^{24}$.

Una de las razones que le motivarían a este autor a reflejar este comentario, se debe seguramente a que la igualdad consagrada en la CE española, haría cambiar una gran cantidad de normas como la que se expresa en el primer ${ }^{25}$ artículo de la Ley 55/1968 que establece que el servicio militar sería realizado por españoles varones.

Dentro de la Ley 85/1978, de 28 de diciembre, de Reales Ordenanzas de las Fuerzas Armadas ${ }^{26}$, se aprecia dos cuestiones que pueden ser objeto de estudio. De forma indirecta y en relación al derecho de igualdad, en su artículo $23^{27}$, se establece que los españo-

http://arbor.revistas.csic.es/index.php/arbor/article/view/1901/2120 (último acceso: 22 de diciembre de 2018)]. Al igual que se ha citado, han pasado ya 30 años desde la incorporación de la mujer a las FAS y, en este período, la evolución normativa ha ido enfocada a equilibrar la igualdad formal y real.

${ }^{22}$ Al igual que refleja María Belén Caballud, «la puesta en práctica de este principio constitucional de igualdad en este ámbito castrense, no fue inmediato" [Vid., CABALLUD HERNANDO, M.B., «Aportación de la mujer militar en las Fuerzas Armadas españolas a la defensa y la seguridad»en

http://arbor.revistas.csic.es/index.php/arbor/article/view/1901/2120 (último acceso: 22 de diciembre de 2018)]. Según se vaya avanzando en el apartado, se irá conociendo las diferentes normativas que se han ido promulgando para poder hacer efectivo este principio. Pese al desarrollo normativo y en base a la opinión de la autora del artículo "hay que seguir trabajando para que la igualdad efectiva entre mujeres y hombres militares sea una realidad completa».

${ }_{23}$ BOE núm. 181, de 29 de julio de 1968, páginas 11083 a 11091 (9 págs. ).

${ }^{24}$ Vid., FERNÁNDEZ SEGADO, F., «El nuevo diseño del servicio militar: la Ley Orgánica 13/1991, de 20 de diciembre», Revista de Administración Pública n. ${ }^{\circ}$ 129, 1992, pág. 86.

${ }_{25}$ Primer artículo de la Ley 55/1968, de 27 de julio, General del Servicio Militar: "El Servicio Militar es un honor y un deber inexcusable que alcanza a todos los españoles varones que reúnan condiciones de edad y aptitud psicofísica. Es, a su vez, un instrumento para la formación espiritual, física y cultural y para lo promoción social de la juventud española».

${ }_{26}$ BOE núm. 11, de 12 de enero de 1979, páginas 753 a 764 (12 págs. ).

27 El artículo 23 establece que: "Los españoles tienen el derecho y el deber de defender España y prestarán el servicio militar en las condiciones que señalen las leyes. El servir a la Patria con las armas es un alto honor y constituye un mérito por los sacrificios que implica» (Ley 85/1978, de 28 de diciembre, de reales ordenanzas de las fuerzas armadas 1979). 
les tienen el derecho de prestar el servicio militar «en las condiciones que señalen las leyes». Si esto último lo relacionamos con su artículo $185^{28}$, donde se consagra que no puede existir ningún tipo de discriminación por razón de sexo, puede surgir la pregunta de: ¿por qué se hace referencia a discriminación por razón de sexo, si la primera mujer no se incorporó hasta 10 años después?. Esta duda puede plantearse ya que, si se compara con el año 1988 que fue cuando se integra la primera mujer en los ejércitos españoles, puede parecer extraño que se determine este principio diez años antes, existiendo únicamente presencia masculina en esta profesión.

Pasados dos años, se estableció el carácter obligatorio del servicio militar "para los españoles», apareciendo reflejado en el artículo $36^{29}$ de la Ley Orgánica 6/1980, de 1 de julio, por la que se regulan los criterios básicos de la defensa nacional y la organización militar $^{30,31}$. No se hace distinción entre hombre y mujer, ya que se generaliza en el texto citado. Aunque esta norma ya hace referencia a la participación de la mujer en la defensa nacional, no hace hincapié en ningún dato más. Asimismo, tampoco se especifica qué cometidos podría desarrollar o dónde. Lo único que establece, y es en su artículo 36, es que «la Ley establecerá la forma de participación de la mujer en la defensa nacional».

Con lo cual, se intenta regular de forma superficial una profesión qué por aquel entonces, estaba hecha solo para el trabajador con sexo masculino ${ }^{32}$. Habría que esperar casi una década, para poder

${ }^{28}$ En el artículo 185 expresa lo siguiente: "En las Fuerzas Armadas ninguno de sus miembros será objeto de discriminación por razón de sexo, raza, nacimiento, religión, opinión o cualquier otra condición personal o social» (Ley 85/1978, de 28 de diciembre, de reales ordenanzas de las fuerzas armadas 1979).

${ }^{29}$ Artículo 36 de la Ley Orgánica 6/1980, de 1 de julio, por la que se regulan los criterios básicos de la defensa nacional y la organización militar: «El servicio militar tendrá para los españoles carácter obligatorio y prioritario sobre cualquier otro servicio que se establezca. La Ley establecerá la forma de participación de la mujer en la defensa nacional».

30 BOE núm. 165, de 10 de julio de 1980 , páginas 15750 a 15753 (4 págs. ).

${ }^{31}$ Reformada parcialmente por Ley Orgánica 1/1984, de 5 de enero, por la que se regulan los criterios básicos de la defensa nacional y la organización militar y, modificada por la Ley Orgánica 5/2005, de 17 de noviembre, de la Defensa Nacional.

${ }_{32}$ Unas de las cuestiones que dieron que hablar en esa época fue la realización del servicio militar por parte de las mujeres. Según cita la Teniente Coronel Cristina Moreno «las diversas sentencias del Tribunal Constitucional sobre este tema aclaran que no existe discriminación en el hecho de que solo el hombre esté obligado a realizar el Servicio Militar, ya que, el criterio de igualdad que señala la Constitución, no significa que todas las Leyes deban aplicarse por igual a sujetos que de por sí son desiguales, como es el caso de la mujer»(Vid., MORENO MARTÍNEZ, C., Mujeres policía, mujeres militares, especial referencia a la mujer Guardia Civil, Madrid, 1998). 
ver la principal normativa que reguló la incorporación de las primeras mujeres al ejército español.

La vía de acceso que se eligió para la integración de la mujer fue el Decreto Ley 1/1988, de 22 de febrero, de incorporación de la mujer a las Fuerzas Armadas ${ }^{33,34}$. La incorporación solo afectó a determinados puestos ${ }^{35}$, en un total de 24 Cuerpos militares. Según se detalla en unas de las Revistas Españolas de Defensa, «en septiembre de 1988, 26 mujeres ingresaban en las Academias y, aunque su acceso se restringía entonces a los Cuerpos de Ingenieros de los Ejércitos y la Armada y a los ahora llamados Cuerpos Comunes -Jurídico, Intervención, Sanidad y Músicos-, era la primera vez que la institución militar acogía a mujeres (...)» ${ }^{36}$. Así, se iniciaría un régimen militar común para ambos sexos, donde la mujer adquiría su condición de militar con pleno derecho ${ }^{37}$.

Comienza un período de integración ${ }^{38}$ a determinados cuerpos y escalas del ejército, realizándose de forma progresiva en el resto de las Unidades militares. En consonancia con Pilar Gallardo, «el resto de cuerpos y escalas existentes en los tres ejércitos y no reseñados en el Real Decreto Ley 1/1988 quedan cerrados al personal femenino hasta que no se produzcan las adaptaciones organizativas y de infraestructuras necesarias» ${ }^{39}$.

A su vez, esta Ley refleja en su texto que las pruebas de acceso se convocarán sin distinción de sexo y que no existirá diferencia alguna

33 BOE núm. 46, de 23 de febrero de 1988, páginas 5672 a 5672 (1 pág. ).

${ }^{34}$ Disposición derogada.

35 Véase artículo 2 del Decreto Ley 1/1988, de 22 de febrero, de incorporación de la mujer a las Fuerzas Armadas.

${ }^{36}$ Vid., F. DEL VADO, S., «30 años de las mujeres en las FAS», Revista española de Defensa, septiembre de 2018, pág. 7 .

37 Los problemas que habría que resolver desde el inicio de la incorporación de la mujer, serían dos principalmente: 1. Quitar cualquier obstáculo en cuanto a la ocupación de determinados destinos por parte de la mujer. 2. Creación de un marco jurídico que facilitase el ingreso de la mujer, así como la permanencia en la profesión militar.

38 En la exposición de motivos de la presente ley se establece esto mismo diciendo: "De acuerdo con estas previsiones procede iniciar el programa de incorporación de la mujer a las Fuerzas Armadas, regulando sin demora su acceso a determinados Cuerpos y Escalas militares. La incorporación de los demás Cuerpos de los Ejércitos se hará de una forma progresiva a medida que se vayan efectuando adaptaciones de diversa índole que, al tiempo que aseguren la adecuada integración, permitan mantener el normal desarrollo de las funciones que las Fuerzas Armadas tienen encomendadas».

39 Vid., GALLARDO RODRÍGUEZ, P., La mujer militar en las Fuerzas Armadas, en El papel de la mujer y el género en los conflictos. Cuadernos de Estrategia n. ${ }^{\circ}$ 157, Instituto español de Estudios Estratégicos, Granada, 2012, pág. 163.

(C) UNED. Revista de Derecho UNED, núm. 24, 2019 
a la hora de que la mujer tenga que ascender ${ }^{40} \mathrm{u}$ ocupar determinados destinos (a excepción de aquellos que por sus condiciones fisiológicas le limiten ocuparlos).

Por todo ello y en palabras de Joaquín López, este hecho ha significado que «la incorporación de la mujer a los ejércitos ha supuesto la ruptura de viejos muros y prejuicios, el enriquecimiento y la modernización de las $F A S_{\gg}{ }^{41}$.

Dentro de las muchas ventajas que suponía la incorporación de la mujer a los ejércitos y sabiendo que éstas representaban la mitad de la población del país, se puede afirmar al igual que expone Pedro Bernal, que "habría más posibilidades de reclutamiento» ${ }^{42,43}$.

Conociéndose que esta Ley no iba a igualar las diferencias, el propio legislador sabía que este solo sería el inicio de un desarrollo legislativo en el que se implementasen medidas para garantizar una igualdad real y efectiva ${ }^{44}$.

\section{Como Complemento a la Ley anterior, la Ley 17/1989, de 19 de julio, Reguladora del Régimen de Personal Militar Profe-}

40 Al igual que expresa Joaquín López de Gea, desde la promulgación de esta Ley, "la mujer ha podido alcanzar todos los empleos militares» (Vid., LÓPEZ DE GEA, J. Derechos Fundamentales y Estatuto Jurídico de las Fuerzas Armadas, Madrid, 2013, pág. 98). Esto último se ha conseguido con el paso de los años.

${ }^{41}$ Vid., LÓPEZ DE GEA, J. Derechos Fundamentales y Estatuto Jurídico de las Fuerzas Armadas, Madrid, 2013, pág. 165.

${ }_{42}$ "La presencia de la mujer en los ejércitos no resulta hasta el momento bastante significativa, si bien se ansía un incremento de su participación militar puesto que puede ser un recurso para paliar las actuales dificultades de reclutamiento" (Cotino Hueso 1999, 370).

${ }^{43}$ Vid., BERNAL GUTIÉRREZ, P., La cultura de seguridad y defensa en España. Sus orígenes y evolución, Cuadernos de Estrategia, 2011, pág. 43.

${ }^{44}$ Así lo establece Joaquín López en su Tesis Doctoral, citando una serie de medidas que el propio legislador desarrollaría para poder alcanzar el fin deseado, que no es otro que el de igualar lo formal con lo material: «a) medidas de flexibilidad horaria, b) de reducción de jornada por razón de guarda legal y lactancia de hijos, c) permisos retribuidos por razones de conciliación, d) medidas para mantener los derechos económicos durante el disfrute de los permisos de paternidad o maternidad, e) aplazamiento de los cursos de capacitación por embarazo o parto, f) medidas de movilidad o de asignación de destino a las víctimas de violencia de género, g) adaptación de los alojamientos militares existentes a la presencia de la mujer, h) creación de centros infantiles para menores de cero a 3 años en establecimientos militares, i) promoción de la presencia de la mujer en los órganos de evaluación, j) adecuación del régimen disciplinario FAS a un nuevo concepto de acoso sexual» (Vid., LÓPEZ DE GEA, J. Derechos Fundamentales y Estatuto Jurídico de las Fuerzas Armadas, Madrid, 2013, pág. 166). Estas medidas se irán viendo según se avance en el análisis histórico-jurídico de la evolución normativa de la mujer en los ejércitos. 
sional $^{45}$ desarrollaría la participación de las mujeres en las FAS en las mismas condiciones que las pruebas de incorporación para los hombres ${ }^{46}$, así como la regulación de la provisión de destinos, donde las condiciones fisiológicas de la mujer podrán determinar algunos puestos de trabajo ${ }^{47}$. Un claro ejemplo se encuentra en las mujeres embarazadas, las cuales, podrán ser cambiadas de puesto por dicha situación, sin suponer despido alguno.

A la hora de tener que promocionar ${ }^{48}$, las mujeres tendrán los mismos requisitos/ condiciones que los hombres: tendrán la posibilidad de llegar a cualquier empleo con las mismas garantías que cualquier persona de sexo masculino. En relación a los empleos, hay que destacar que esta Ley "posibilitó que las mujeres accedieran, como oficiales y suboficiales, a las llamadas armas combatientes» ${ }^{49}$.

Con esta norma, se fue poniendo de manifiesto la nueva regulación que tendrían las mujeres para poder optar a los mismos derechos que los hombres. Se fue estableciendo paulatinamente un marco normativo que permitiera equiparar las oportunidades de las mujeres, con las que cuentan los hombres en esta organización.

En consonancia con lo citado anteriormente, referente a la defensa de España, y acorde con el artículo 2 de la Ley Orgánica 6/1980, se dice que: "La defensa nacional es la disposición, integración y acción coordinada de todas las energías y fuerzas morales y ma-

45 Ley 17/1989, 19 julio, derogada por el número 1 de la Disposición Derogatoria Única de la Ley 17/1999, 18 mayo, de Régimen del Personal de las Fuerzas Armadas («B.O.E.» 19 mayo), el 20 de mayo de 1999. Téngase en cuenta que la presente Ley fue derogada en su aplicación al Cuerpo de la Guardia Civil, por Ley 42/1999, 25 noviembre, de Régimen del Personal del Cuerpo de la Guardia Civil («B.O.E.» 26 noviembre).A su vez, ésta última fue derogada por la Ley 29/2014, de 28 de noviembre, de Régimen del Personal de la Guardia Civil.

${ }_{46}$ En el Séptimo párrafo del preámbulo de la Ley 17/1989, se expone: «(...) Así se reguló, en cumplimiento del mandato positivo contenido en nuestro ordenamiento legal, la participación de la mujer en los Cuerpos y Escalas militares en un plano de igualdad con los sistemas de incorporación de los hombres, con lo que se puso en marcha una de las medidas orientadas a eliminar los obstáculos que se oponían a la plena efectividad del principio constitucional de igualdad (...)».

47 En el artículo 74.5 de Ley 17/1989, se puede leer que: "Las normas de provisión de destinos podrán establecer particularidades para la mujer derivadas de sus condiciones fisiológicas específicas. Durante el período de embarazo se podrá asignar, por prescripción facultativa, un puesto orgánico distinto del que estuviere desempeñando (...)».

48 En el artículo 89.4 de Ley 17/1989, se establece lo siguiente: «Las evaluaciones de tipo profesional, y consiguientes clasificaciones, que afecten a la mujer harán abstracción de lo dispuesto en el artículo 74.5 de esta Ley, con el fin de garantizar iguales posibilidades de progresión que las de los hombres de la misma Escala».

${ }^{49}$ Vid., F. DEL VADO, S., «30 años de las mujeres en las FAS», Revista española de Defensa, septiembre de 2018, pág. 8.

(c) UNED. Revista de Derecho UNED, núm. 24, 2019 
teriales de la Nación, ante cualquier forma de agresión» y destacando a su vez que, deben "todos los españoles participar en el logro de tal fin»; se puede ver cómo con el artículo 11.2 de la Ley Orgánica 13/1991, de 20 de diciembre, del Servicio Militar ${ }^{50}$, que establece que «las mujeres están exentas del servicio militar. Podrán ser llamadas a cumplir determinados servicios en las Fuerzas Armadas, de conformidad con la legislación reguladora de la movilización nacional», se entra más en detalle al especificar la forma en la cual, la mujer podría participar en la defensa del país. Aun no aclarando su participación, deja claro que sería regulado por ley.

Asimismo, hace una aclaración estableciendo en su preámbulo ${ }^{51}$ que «la mujer queda excluida de la obligatoriedad del servicio militar porque las necesidades de la defensa militar quedan cubiertas con el concurso de los varones». Debido a ello, la mujer no tendría que realizar el servicio militar obligatorio establecido en la Ley de 1980. En palabras de Luis Alberto Pomed Sánchez ${ }^{52}$, «la prestación del servicio militar alcanza únicamente a los varones y durante un período de su vida concreto» ${ }^{53}$.

Siguiendo con la incorporación femenina al ejercicio profesional en las FAS, es con el Real Decreto 984/1992, de 31 de julio, por el que se aprueba el Reglamento de Tropa y Marinería $^{54}$, cuando el sexo femenino optaría a ocupar puestos en este ámbito. Destacar su artículo $25^{55}$ por establecer que la mujer podía optar a cualquier destino, exceptuando aquellos que fueran actividades con una calificación táctica u operativa. Con esta norma, se amplía en gran medida

50 BOE núm. 305, de 21 de diciembre de 1991, páginas 41246 a 41253 (8 págs. ).

51 Párrafo séptimo de la Ley Orgánica 13/1991, de 20 de diciembre, del Servicio Militar: "La mujer queda excluida de la obligatoriedad del servicio militar porque las necesidades de la defensa militar quedan cubiertas con el concurso de los varones y por considerar que esta decisión no vulnera el mandato de no discriminación establecido en el artículo 14 de la Constitución, de acuerdo con la doctrina del Tribunal Supremo, del Tribunal Constitucional y del Tribunal Europeo de Derechos Humanos. No obstante, las mujeres podrán incorporarse a las tareas de la defensa nacional con arreglo a las normas sobre movilización nacional».

${ }^{52}$ Luis Alberto Pomed Sánchez es letrado del Tribunal Constitucional y profesor titular de Derecho Administrativo de la Universidad de Zaragoza.

${ }^{53}$ Vid., POMED SÁNCHEZ, L.A., "Objeción, Insumisión y servicio militar obligatorio», Revista de Administración Pública n. ${ }^{\circ}$ 134, 1994, pág. 214.

${ }^{54}$ BOE núm. 209, de 31 de agosto de 1992, páginas 30037 a 30042 (6 págs. ).

55 Artículo 25. Destinos del personal femenino. "El personal femenino de tropa y marinería profesionales podrá optar a todos los destinos de su empleo militar excepto los de tipo táctico u operativo en Unidades de La Legión, de operaciones especiales, paracaidistas y cazadores paracaidistas. Tampoco podrán formar parte de las fuerzas de desembarco, de las dotaciones de submarinos ni de buques menores en los que sus condiciones estructurales no permitan el alojamiento en condiciones adecuadas». 
el abanico de posibilidades que tenían las mujeres a la hora de elegir un puesto de trabajo. En tan solo cuatro años, se hace posible que la mujer de los ejércitos ocupe la mayoría de los destinos posibles.

Aunque las leyes que se han citado hasta el momento, establecen los primeros pasos de la mujer en esta profesión, fue con la Ley 17/1999, de 18 de mayo, de Régimen de Personal de las Fuerzas Armadas donde se consiguió establecer el principio de igualdad en todos sus sentidos, sin establecerse discriminación alguna por razón de sexo $^{56}$. Estos cambios provocaron un gran avance en materia de igualdad, al eliminar ${ }^{57}$, una de las barreras que tenían el sexo femenino por entonces, la limitación de determinados destinos ${ }^{58}$ por razón de sexo. Aun así, no se impedía que formaran parte de Unidades operativas/combate, con lo que garantizaban lo consagrado en la Exposición de Motivos de la Ley ${ }^{59}$. Con lo cual, al no establecerse límite alguno para poder ocupar un puesto determinado dentro de las FAS, se podría afirmar, al igual que expresa Pilar Gallardo, que «se consigue asi la plena integración de la mujer en las FAS españolas» ${ }^{60}$.

Por otro lado, y en consonancia con Ley 17/1989, de 19 de julio, aquellas mujeres profesionales que estén en período de embarazo, se les podrá asignar un puesto de trabajo adaptado a su situación, sin

${ }^{56}$ Las principales consecuencias tras la promulgación fueron:1. La prestación del servicio militar que era únicamente obligatorio para hombres, quedaría suspendida. 2. Se eliminarían todos aquellos requisitos que limitasen la posibilidad de ocupar un determinado puesto de trabajo, con lo cual, la carrera profesional de hombres y mujeres tendrían iguales condiciones para promocionar, al no existir límite alguno, más que las propias condiciones fisiológicas.

57 "La entrada en vigor en 1999 de la Ley 17/1999, de 18 de mayo, de Régimen de Personal de las Fuerzas Armadas, encargada de regular la carrera militar de ambos sexos, supuso que a partir de ese momento ningún destino quedara vetado a las féminas. Fue el impulso que necesitaban» (Vid., ALCANTARA LÓPEZ, R, y DEL POZO CRUZ, J.T., "La mujer en las Fuerzas Armadas españolas: la evolución normativa como piedra angular», Investigación y género, logros y retos: III Congreso Universitario nacional. Investiación y género, Sevilla, 2011, pág. 51).

${ }_{58}$ Aunque esta Ley dejaba de lado cualquier aspecto que pudiera limitar el destino de una mujer a un puesto de trabajo determinado, éstas no podrían ser obligadas a pertenecer a Unidades de fuerza, a excepción de que ellas hubiesen aprobado esta decisión.

59 «Además España es uno de los únicos catorce países, junto con Alemania, Australia, Canadá, Corea del Sur, Dinamarca, Finlandia, Francia, Estados Unidos, Israel, Nueva Zelanda, Polonia, Rumanía y Suecia., que no se opone a la participación de las militares en puestos de combate» (Vid., GARCÍA SÁNCHEZ, B., "Integración real e instrumentalización de la imagen de la mujer en las Fuerzas Armadas españolas», Journal of feminist, gender and women studies, 2016, pág. 26).

${ }^{60}$ Vid., GALLARDO RODRÍGUEZ, P., La mujer militar en las Fuerzas Armadas, en El papel de la mujer y el género en los conflictos. Cuadernos de Estrategia n. ${ }^{\circ}$ 157, Instituto español de Estudios Estratégicos, Granada, 2012, pág. 163.

(C) UNED. Revista de Derecho UNED, núm. 24, 2019 
que esto pueda suponer pérdida de destino. Con ello, se permitía que la mujer que quisiera tener hijos y quedase embarazada, pudiera desarrollar y compatibilizar su vida personal y profesional con garantías.

Por todo lo anterior, es importante resaltar en palabras de María Belén Caballud Hernando ${ }^{61}$, lo anteriormente expuesto, y que dice: "este momento constituye la clave del proceso iniciado en 1988, en tanto que se consigue la plasmación jurídica de la igualdad formal entre las mujeres y los hombres en las Fuerzas Armadas, este hecho es jurídicamente muy importante» ${ }^{62}$.

La eliminación de la mayor parte de los «obstáculos» presentes en ese momento que dificultaban alcanzar la igualdad efectiva, conllevó un aumento considerable de las cifras de efectivos de mujeres, al ingresar un gran número de éstas. Con la Ley de Régimen del Personal de las FAS, «se eliminaron todas las restricciones, permitiendo el acceso de la mujer a todos los cuerpos, escalas y destinos. Ello produjo un acceso masivo en esos años: más de 4.600 mujeres ingresaron en los Ejércitos entre 1998 y 2000, otras 3.500 hasta 2002 y unas 1.300 hasta $2005 »^{63}$.

Al objeto de facilitar la incorporación e integración de la mujer a los ejércitos, se promulgó la ORDEN DEF/524/2005 ${ }^{\mathbf{6}}$, de 7 de marzo, por la que se dispone la publicación del Acuerdo de Consejo de Ministros de 4 de marzo de 2005, por el que se aprueban medidas para favorecer la incorporación y la integración de la mujer en las Fuerzas Armadas. Entre las actuaciones reflejadas, se encuentran: la creación del Observatorio de la Mujer $^{65}$ y un Comité que coordine todos los aspectos referentes a ella, al objeto de mejorar la integración, adaptación y promoción de todas aquellas que se unían a las FAS y, una de las principales medidas,

${ }^{61}$ María Belén Caballud fue vocal del observatorio militar de igualdad Ministerio de Defensa de España en el año 2014.

${ }^{62} \mathrm{Vid}$., CABALLUD HERNANDO, M.B., "Aportación de la mujer militar en las Fuerzas Armadas españolas a la defensa y la seguridad» en

http://arbor.revistas.csic.es/index.php/arbor/article/view/1901/2120 (último acceso: 22 de diciembre de 2018).

${ }^{63} \mathrm{Vid}$., F. DEL VADO, S., "30 años de las mujeres en las FAS», Revista española de Defensa, septiembre de 2018, pág. 8.

${ }_{64}$ BOE núm. 57, de 8 de marzo de 2005, páginas 8109 a 8110 (2 págs. ).

65 Con la Orden Ministerial 51/2011, de 28 de julio, por la que se cambia la denominación del Centro de Estudio sobre la situación de la Mujer en las Fuerzas Armadas (Observatorio de la Mujer en las FAS) por Observatorio militar para la igualdad entre mujeres y hombres en las Fuerzas Armadas y se regula su estructura y funcionamiento. 
fue la apertura de guarderías ${ }^{66}$ en los centros militares. Esto último permitiría conciliar la vida familiar en gran medida.

A pesar que la norma no es de gran extensión, incluye una serie de medidas que hacen mejorar las condiciones del personal femenino. Como expresa Joaquín López «(...) trataba de llamar la atención de las mujeres que buscaban su primer empleo, trataba de lanzar el mensaje de que el Ejército era una buena opción laboral y para ello aprueba una serie de medidas que favorecen su incorporación e integración ${ }^{67}$.

Junto a la CE, otra de las normas que han servido de base para construir un marco normativo de igualdad y que han tenido mayor impacto social sería la Ley Orgánica 3/2007, de 22 de marzo, para la igualdad efectiva de mujeres y hombres (LOIEMH). Esta Ley dedica dos artículos exclusivamente para las FAS, donde se consagra el principio de igualdad. El primero ${ }^{68}$ de ellos, aplica este principio en todas las esferas del trabajo ${ }^{69}$. El segundo de los

${ }^{66}$ Aunque pueda pensarse que la apertura de guarderías fue una medida orientada a facilitar la conciliación de la vida familiar de as mujeres, autores como María Belén Caballud opinan «que ha servido para poner en funcionamiento, en colaboración con las CC.AA. este tipo de centros de enseñanza en establecimientos militares para facilitar la conciliación de la vida personal y profesional de los hombres y las mujeres que prestan servicio en nuestras Fuerzas Armadas» [Vid., CABALLUD HERNANDO, M.B., "Aportación de la mujer militar en las Fuerzas Armadas españolas a la defensa y la seguridad» en

http://arbor.revistas.csic.es/index.php/arbor/article/view/1901/2120 (último acceso: 22 de diciembre de 2018)]. Como se verá más adelante, estas ayudas irán de la mano de lo citado en el preámbulo de la Ley Ley 39/2007, de la Carrera Militar, estableciéndose que «se pretende conjugar la disponibilidad permanente para el servicio, específica de los militares, con la conciliación de la vida profesional, personal y familiar».

${ }^{67}$ Vid., LÓPEZ DE GEA, J. Derechos Fundamentales y Estatuto Jurídico de las Fuerzas Armadas, Madrid, 2013, pág. 170.

${ }^{68}$ Ley Orgánica 3/2007, de 22 de marzo, para la igualdad efectiva de mujeres y hombres. Artículo 65. Respeto del principio de igualdad: "Las normas sobre personal de las Fuerzas Armadas procurarán la efectividad del principio de igualdad entre mujeres y hombres, en especial en lo que se refiere al régimen de acceso, formación, ascensos, destinos y situaciones administrativas».

69 "En perspectiva comparada internacional, como en España, también en Alemania, Bélgica, Bulgaria, Canadá o Dinamarca se ha logrado legislar para que la inserción de las mujeres en sus ejércitos se lleve a cabo sin restricciones de ningún tipo. Esta situación, sin embargo, no es común a todos los ejércitos. Algunos mantienen restricciones, bien de destinos o bien de puestos a ocupar por las militares. Concretamente, EEUU, pese a ser pionero en impulsar ciertas medidas de integración a todos los cuerpos y empleos militares, restringe la adscripción de mujeres a unidades de choque, apartándolas de destinos terrestres para el combate cuerpo a cuerpo» (Vid., AGUDO ARROYO, Y., «La participación de las mujeres en las Fuerzas Armadas españolas: de la incorporación a la integración», Revista Internacional de Trabajo Social y Ciencias Sociales, 2014, pág. 18). 
$\operatorname{artículos}^{70}$, materializa la necesidad de hacer extensivo a estas Unidades, aquellas normas en materia de violencia de género, conciliación familiar y profesional, que permitan mejorar la situación de la mujer en los ejércitos.

Dentro de su texto, presenta una serie de modificaciones de especial relevancia frente a la Ley 17/1999, de 18 de mayo, de Régimen del Personal de las Fuerzas Armadas, la cual es modificada en alguno de sus aspectos como: se lleva a cabo una política protectora sobre la mujer, en todas las etapas relacionadas con el embarazo, como son el parto, posparto y el propio período de gestación, en aquellas situaciones relacionadas con los ascensos. Asimismo, se podrá asignar un nuevo puesto de trabajo al objeto de poder ajustarse a su nueva situación. Se mejoran las opciones en el momento de solicitar la excedencia voluntaria, ya que añaden nuevos supuestos como los cuidados de algún familiar distinto al de los hijos o la posibilidad de agrupamiento familia en las condiciones establecidas por la Ley.

En consonancia con esta Ley, surge la Ley 39/2007 de 19 de noviembre de la carrera militar ${ }^{71},{ }^{72}$. En ella se siguen estableciendo nuevas normas que favorezcan la conciliación familiar, ya que repercute directamente en la decisión de poder o no ingresar a este tipo de trabajos. Hace un esfuerzo por mejorar las condiciones sobre el acceso ${ }^{73}$, formación y progresión en la carrera militar de ambos sexos. Con respecto a la situación de embarazo ${ }^{74}$, sigue mejorando las condiciones de protección para intentar que este hecho no le suponga una desventaja a la hora de promocionar (artículo 6) y busca

${ }^{70}$ Ley Orgánica 3/2007, de 22 de marzo, para la igualdad efectiva de mujeres y hombres. Artículo 66. Aplicación de las normas referidas al personal de las Administraciones públicas. "Las normas referidas al personal al servicio de las Administraciones públicas en materia de igualdad, prevención de la violencia de género y conciliación de la vida personal, familiar y profesional serán de aplicación en las Fuerzas Armadas, con las adaptaciones que resulten necesarias y en los términos establecidos en su normativa específica».

${ }^{71}$ BOE núm. 278, de 20/11/2007.

${ }^{72}$ Ley 46/2015, de 14 de octubre, por la que se modifica la Ley 39/2007, de 19 de noviembre, de la carrera militar, publicado en el $B O E$ núm. 247, de 15 de octubre de 2015, páginas 95785 a 95791 (7 págs. ).

${ }^{73}$ Por ejemplo, como se deriva del artículo 56 de la norma a desarrollar, a la hora de ingresar en las academias, no podrá haber diferencia alguna entre hombres y mujeres, salvo las derivadas de las condiciones físicas de cada uno de ellos.

${ }_{74}$ Otras leyes que adapta la posición de la mujer en este tipo de situaciones serían El RD 293/2009 de 6 de marzo por el que se aprueban medidas de protección de la maternidad en el ámbito de enseñanza de las Fuerzas Armadas y Orden $\mathrm{DEF} / 253 / 2015$, de 9 de febrero, por la que se regula el régimen de vacaciones, permisos, reducciones de jornada y licencias de los miembros de las Fuerzas Armadas. 
así, soluciones alternativas ${ }^{75}$ a éstas para poder equipararlas a las oportunidades de los hombres.

Por otro lado, dentro de los códigos deontológicos con los que cuenta la normativa española, se puede hacer referencia dentro de este texto al Real Decreto 96/2009, de 6 de febrero, por el que se aprueban las Reales Ordenanzas para las Fuerzas Armadas $^{\mathbf{7 6}}$. Continuando con el principio de igualdad, éste se consagra en el artículo $13^{77}$ de la Ley citada, al igual que la prohibición de toda discriminación (artículo 73) ${ }^{78}$. Además de lo anterior, el único artículo que referencia a la mujer es aquel que establece la protección a la población más vulnerable, donde se encuentran entre otros, mujeres y niños.

Está claro que el primer paso es la norma y el segundo, su aplicación. Pero el problema en muchas ocasiones, es la no efectividad de la norma, es decir, no ejecutarla "sobre el terreno».

Pese a esto último, la sucesión de leyes citadas ha puesto de manifiesto que muchas de ellas han tomando medidas directas sobre la mujer. Se puede observar cómo en el principio de la in-

75 Estas soluciones alternativas, no dejan de ser acciones positivas que en palabras de María Belén Caballud estarían relacionadas con «las situaciones derivadas de la maternidad al protegerlas en diferentes momentos de la carrera militar (ingreso, ascenso, situaciones, enseñanza de formación y perfeccionamiento, destinos), regula la conciliación de la vida profesional, personal y familiar de los miembros de las Fuerzas Armadas, y asegura la representación de la mujer militar en los órganos de evaluación para la selección, ascenso y asignación de destinos» [Vid., CABALLUD HERNANDO, M.B., "Aportación de la mujer militar en las Fuerzas Armadas españolas a la defensa y la seguridad» en

http://arbor.revistas.csic.es/index.php/arbor/article/view/1901/2120 (último acceso: 22 de diciembre de 2018)].

${ }^{76}$ Este es un texto que recoge los principios éticos y valores que debe tener todo militar en su trabajo diario, para que sirva como ejemplo para el resto de los ciudadanos. Como muy bien expresa María Belén Caballud, "deben servir de guía a todos los militares para fomentar el exacto cumplimiento del deber, inspirado en el amor a España y en el honor, disciplina y valor» [Vid., CABALLUD HERNANDO, M.B., «Aportación de la mujer militar en las Fuerzas Armadas españolas a la defensa y la seguridad» en

http://arbor.revistas.csic.es/index.php/arbor/article/view/1901/2120 (último acceso: 22 de diciembre de 2018)].

77 Artículo 13. Igualdad de género. "Velará por la aplicación de los criterios y normas relativos a la igualdad efectiva de mujeres y hombres y a la prevención de la violencia de género».

78 Artículo 78. Convivencia en su Unidad. "Velará por la convivencia entre todos sus subordinados sin discriminación alguna por razón de nacimiento, origen racial o étnico, género, orientación sexual, religión o convicciones, opinión o cualquier otra condición o circunstancia personal o social, fomentando el compañerismo y la integración intercultural». 
tegración se han promulgado un mayor número de normas que en los últimos años. Con esto se quiere decir que, a día de hoy, no haría falta un desarrollo tan exhaustivo como en los inicios de la incorporación. Esto se debe a que todas las leyes establecidas han permitido acercar a la mujer a una igualdad real y efectiva con el hombre.

En relación a la transversalidad ${ }^{79}$ de género, la Ley Orgánica 9/2011, de 27 de julio, de derechos y deberes de los miembros de las Fuerzas Armadas ${ }^{80}$, es una de las más relevantes por el impacto profesional que tiene sobre el personal integrado en las FAS. En aplicación de la LOIEMH y la Ley de la Carrera Militar, esta Ley refleja en varios artículos los principios ${ }^{81}$ transversales de igualdad y no discriminación dentro de la carrera militar.

\section{ESTADÍSTICA DEL PERSONAL DE LAS FAS}

Una forma visual y rápida de poder ver la Evolución de la mujer en las FAS, es analizando la estadística ${ }^{82}$. A continuación, se incorpora un gráfico que expresa claramente la evolución de la mujer en estas Unidades militares. Asimismo, se analiza brevemente los valores principales que se han extraído y que se incorporan en la tabla que se ve posteriormente.

79 Ya no solo se queda en el hecho de citar este principio de igualdad, sino que en su artículo 4.2. se expresa la obligación de que aquellas autoridades competentes en esta materia, se aseguren de poder promover la igualdad de oportunidades entre hombres y mujeres. Este precepto tiene relación directa con el artículo 9.2 de la CE que promueve a su vez, que los poderes públicos favorezcan el derecho de la igualdad para alcanzar una efectividad del mismo.

${ }^{80}$ BOE núm. 180, de 28/07/2011.

${ }^{81}$ Se destaca en el texto de esta Ley el principio de igualdad y así lo resalta María Belén Caballud diciendo que esta norma "reconoce expresamente el principio de igualdad y no discriminación por razón de sexo, u orientación sexual, así como el deber de promover las medidas necesarias para garantizar que, la igualdad entre el hombre y la mujer sea real y efectiva especialmente en el acceso, la prestación del servicio, la formación y la carrera militar» [Vid., CABALLUD HERNANDO, M.B., «Aportación de la mujer militar en las Fuerzas Armadas españolas a la defensa y la seguridad» en

http://arbor.revistas.csic.es/index.php/arbor/article/view/1901/2120 (último acceso: 22 de diciembre de 2018)]. Un punto a señalar en la segunda parte de esta cita es el deber de "promover las medidas necesarias», paso que se considera intermedio para alcanzar una igualdad efectiva.

82 Estos datos se extraen de la página Web del Ministerio de Defensa en relación al Observatorio militar para la igualdad entre mujeres y hombres en las Fuerzas Armadas (Ministerio de Defensa 2018). 


\section{$\partial m=$ \\ INFORME ANUAL 2017}

\section{EVOLUCIÓN DE LA MUJER EN LAS FUERZAS ARMADAS}

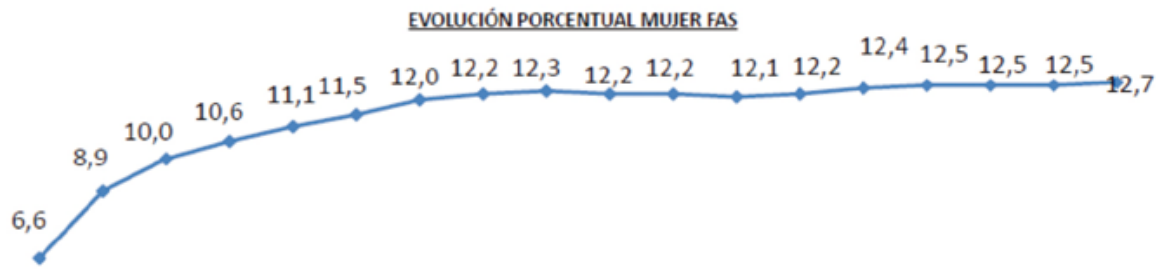

200020012002200320042005200620072008200920102011201220132014201520162017

Fuente: Ministerio de Defensa ${ }^{83}$

Imagen 1. Evolución de la mujer

Aunque solo se cuenta con porcentajes desde el año 2000, se puede entender que la evolución de efectivos de la mujer desde su incorporación en el año 1988, hasta prácticamente el 2005/06, ha sido progresiva y a su vez, lenta.

Como veremos a continuación en la siguiente tabla, en tan solo veinte años se incorporan casi dieciséis mil mujeres a las FAS, haciendo una media anual de ochocientos efectivos.

En función de quién lo analice, puede interpretar la cifra de manera positiva o negativa. Hay que recordar que en esos años ha habido un continuo cambio legislativo, medios logísticos, protocolos y programas de adaptación e instrucción, etc. para poder hacer efectiva la incorporación de la mujer a los ejércitos y, sobretodo, conseguir que la mismo alcance una igualdad tanto formal como real.

${ }^{83}$ Vid., Observatorio militar para la igualdad entre mujeres y hombres en las Fuerzas Armadas: http://www.defensa.gob.es/ministerio/organigrama/subdef/omi/ (último acceso: 25 de diciembre de 2018).

(C) UNED. Revista de Derecho UNED, núm. 24, 2019 
Pero alejándose de este hecho se considera más importante la segunda parte de la gráfica, en concreto, el tramo que transcurre desde el año 2006 hasta el final. Obviamente, se ve prácticamente una línea recta que indica que la proporción de efectivos se ha mantenido de forma constante. La curva de crecimiento se ha convertido en una línea constante. Por todo ello, habría que preguntarse lo siguiente: ¿Por qué no ingresan más efectivos? ¿Hay campañas de captación hacia la mujer?

Estas preguntas también se pueden referenciar hacia la siguiente tabla que contiene los números de efectivos y porcentajes desde el año 2006 hasta la actualidad.

Tabla 1. Número de efectivos en las FAS (elaboración propia)

\begin{tabular}{lccccc}
\hline & $\begin{array}{c}\text { TOTAL } \\
\text { EFECTIVOS } \\
\text { FUERZAS } \\
\text { ARMADAS }\end{array}$ & MUJERES & HOMBRES & \% MUJERES & $\%$ HOMBRES \\
\hline 2006 & 121.781 & 14.519 & 107.262 & 11,92 & 88,08 \\
2007 & 122.000 & 14.967 & 107.033 & 12,26 & 87,74 \\
2008 & 123.668 & 15.165 & 108.503 & 12,26 & 87,74 \\
2009 & 131.946 & 15.947 & 115.999 & 12,08 & 87,92 \\
2010 & 130.964 & 15.978 & 114.986 & 12,20 & 87,80 \\
2011 & 126.926 & 15.551 & 111.375 & 12,25 & 87,75 \\
2012 & 124.357 & 15.313 & 109.044 & 12,31 & 87,69 \\
2013 & 121.753 & 15.149 & 106.604 & 12,44 & 87,56 \\
2014 & 121.861 & 15.154 & 106.707 & 12,43 & 87,57 \\
2015 & 121.586 & 15.144 & 106.442 & 12,45 & 87,55 \\
2016 & 120.647 & 15.147 & 105.500 & 12,55 & 87,45 \\
2017 & 117.761 & 14.997 & 102.764 & 12,73 & 87,27 \\
2018 & 120.596 & 15.286 & 105.310 & 12,71 & 87,29 \\
\hline
\end{tabular}

Fuente: Instituto de la Mujer y para la Igualdad de Oportunidades

En esta tabla se representan los datos desde hace más de una década. Desde el año 2006 hasta nuestros días, se mantiene un porcentaje similar de mujeres en las FAS. Al igual que se ha planteado antes, se debe enfocar todos los estudios a dar respuesta a los motivos que han provocado este mantenimiento de cifras. 
Aun así, el ligero aumento del porcentaje en las mujeres, se debe a que los últimos años ha ido descendiendo el número de efectivos de sexo masculino, ya que el número de las mujeres se ha mantenido.

Por otro lado, y en relación a los empleos que ostentan las mujeres en los ejércitos, se pueden tratar una serie de consideraciones de interés público, como puede ser, la ocupación de puestos de mando por parte del sexo femenino y, que se ve en la tabla siguiente.

Tabla 2. Porcentajes de efectivos por escalas (elaboración propia)

\begin{tabular}{cccc}
\hline & OFICIALES & SUBOFICIALES & $\begin{array}{c}\text { TROPA Y } \\
\text { MARINERIA }\end{array}$ \\
\cline { 2 - 4 } & $\%$ & $\%$ & $\%$ \\
\hline 2006 & 5,4 & 2,5 & 17,7 \\
2008 & 5,61 & 1,17 & 18 \\
2009 & 5,9 & 1,5 & 17,7 \\
2010 & 6,0 & 1,8 & 17,1 \\
2011 & 6,2 & 2,8 & 16,9 \\
2012 & 6,5 & 2,7 & 17 \\
2013 & 7,3 & 3,2 & 16,9 \\
2014 & 7,6 & 3,6 & 16,9 \\
2015 & 7,9 & 3,9 & 16,7 \\
2016 & 8,2 & 4,3 & 16,5 \\
2017 & 8,0 & 4,6 & 16,5 \\
2018 & 8,6 & 4,9 & 16,6 \\
\hline
\end{tabular}

Fuente: Ministerio de Defensa ${ }^{84}$

Se puede ver a simple vista, cómo los empleos de suboficial y oficial van aumentando paulatinamente con el paso del tiempo. Esto puede suceder por dos motivos: la primera de ellas, la promoción desde empleos inferiores o, por otro lado, que accedan directamente a escalas de mando.

${ }^{84} \mathrm{Vid}$., Observatorio militar para la igualdad entre mujeres y hombres en las Fuerzas Armadas: http://www.defensa.gob.es/ministerio/organigrama/subdef/omi/ (último acceso: 25 de diciembre de 2018). 
Ya en los años 2007-2008 hay 148 comandantes, ascendiendo la primera mujer al empleo de Teniente Coronel en el año 2009. Con el paso de los años ha aumentado su número en dicho empleo ${ }^{85}$, pasando de 5 efectivos (2011) a 69 (2015) en tan solo cuatro años ${ }^{86}$.

La primera militar oficial en España se llama Patricia Ortega García (Madrid, 1963). En 2009 alcanzó el empleo de Teniente Coronel y actualmente es la mujer con mayor empleo en las FAS, al ascender a coronel en 2015. Junto con la Capitán Rosa María García-Malea ${ }^{87}$ (primera mujer en pilotar un caza de combate), hay que destacar a Gala Gallego $^{88}$ (primera mujer en mandar una Unidad del Ejército de Tierra en zona de conflicto) y la Capitán de Fragata Esther Yáñez (primera mujer al mando de un buque militar) son consideradas dentro de las fuerzas armadas, como pioneras, entre otras.

Siguiendo con el análisis estadístico se puede prever que, con el paso del tiempo seguirá en aumento el número de efectivos en la

85 «Por lado debe advertirse que de las doce mujeres que en 2012 habian conseguido graduarse como teniente coronel, tan solo una de ellas lo había hecho dentro del Ejército de Tierra y dos en el de Aire. Las otras nueve lo habian hecho dentro de los llamados Cuerpos Comunes, es decir, aquellas especialidades que no forman parte de ninguno de los tres ejércitos y a las que se accede mediante una titulación específica para desempeñar funciones sanitarias, jurídicas, técnicas o musicales. De hecho en 2015 se sigue dando la circunstancia de que, si bien en su conjunto las mujeres representan un 12,4\% del total de efectivos de las Fuerzas Armadas, ese porcentaje se incrementaba hasta el 21,9\% en los Cuerpos Comunes» (Vid., GARCÍA SÁNCHEZ, B., «Integración real e instrumentalización de la imagen de la mujer en las Fuerzas Armadas españolas», Journal of feminist, gender and women studies, 2016, pág. 26).

${ }^{86} \mathrm{Vid}$., Observatorio militar para la igualdad entre mujeres y hombres en las Fuerzas Armadas: http://www.defensa.gob.es/ministerio/organigrama/subdef/omi/ (último acceso: 25 de diciembre de 2018).

87 Dentro de las numerosas referencias que se pueden citar de esta militar, se puede encontrar: "A los 21 superó las pruebas de ingreso en la Academia General del Aire. En 2006 se convirtió en la primera piloto de caza del Ejército español a bordo de un F-5, y un año después, destinada en el Ala 15 de Zaragoza, sería la primera en volar un F-18 (...), ha obtenido la más alta cualificación en el Programa Táctico de Liderazgo de la OTAN». En palabras de Rosa María, se sabe que no ha tenido dificultades en su trayectoria profesional por la condición de su sexo, pero si afirma, que al igual que el resto, han tenido las mismas dificultades para poder conseguir los logros obtenidos. No obstante, reconoce en alguna entrevista que, el tener 3 hijos, condiciona bastante la trayectoria profesional. Con ello afirma que se debería seguir trabajando en materia de igualdad y, en especial, en materia de conciliación laboral (Vid., F. DEL VADO, S., «30 años de las mujeres en las FAS», Revista española de Defensa, septiembre de 2018, pág. 9).

88 Entre los motivos que se destacan de Gala Gallego en la Revista Española de Defensa en relación al bajo número de efectivos de mujeres, se encuentra: «el desconocimiento, y porque tradicionalmente ha sido una profesión de hombres. Pero esto ha cambiado. También porque es una profesión que requiere disponibilidad ante el servicio, movilidad y formación física» (Vid., F. DEL VADO, S., "30 años de las mujeres en las FAS», Revista española de Defensa, septiembre de 2018, pág. 10). 
Escala de Oficiales y Suboficiales, ya que la trayectoria mantenida hasta el momento es creciente.

Las cifras en términos absolutos pueden considerarse bajas pero, comparando los datos con el resto de países de la OTAN, se puede observar que están en consonancia. Aunque la mujer se ha incorporado a las FAS más tarde que en otros países, se cuenta con un mayor número de efectivos. Es decir, aun siendo su integración más reciente, han aumentado de forma más rápida el número. Como se deriva de los datos de la tabla que hay a continuación, España está únicamente detrás de países referentes como son Estados Unidos y Francia ${ }^{89}$.

\section{Mujeres en las Fuerzas Armadas de la OTAN}

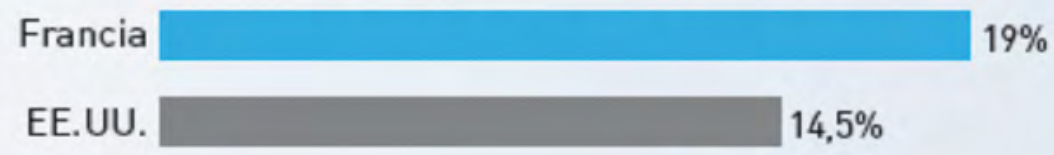

ESPAÑA $\square 12,7 \%$

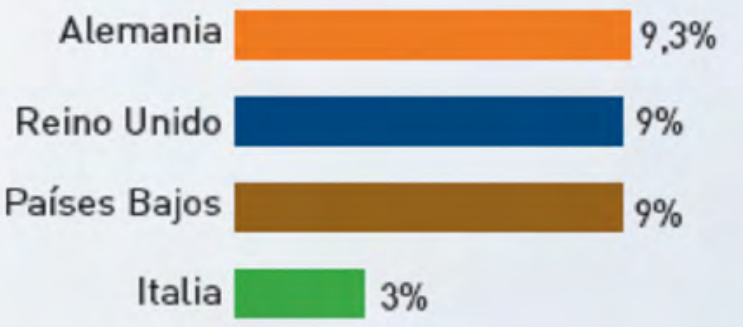

Fuente: Revista Española de Defensa ${ }^{90}$

Imagen 2. Porcentajes de las mujeres en las FAS de la OTAN

89 «En perspectiva comparada internacional, las Fuerzas Armadas españolas coinciden con las de otros países con más larga experiencia en cuando a la inserción de las mujeres a los Ejércitos, como es el caso de Estados Unidos o Canadá. En todos ellos, se observa una mayor representación de mujeres en los cuerpos comunes de las Fuerzas Armadas, frente a otros puestos como son los de combate» (Vid., AGUDO ARROYO, Y., "La participación de las mujeres en las Fuerzas Armadas españolas: de la incorporación a la integración», Revista Internacional de Trabajo Social y Ciencias Sociales, 2014, pág. 22). "El porcentaje de mujeres en nuestras Fuerzas Armadas, del 12,7 por 100, supera al de la media de los países de la OTAN, que es del 10,9 por 100. Dicha cifra se encuentra por debajo de la de las naciones con mayor experiencia en este ámbito - EEUU y Francia-, pero por encima de otras, como Alemania, Italia, Países Bajos o Reino Unido» (Vid., F. DEL VADO, S., «30 años de las mujeres en las FAS», Revista española de Defensa, septiembre de 2018, pág. 8).

${ }^{90}$ Vid., F. DEL VADO, S., «30 años de las mujeres en las FAS», Revista española de Defensa, septiembre de 2018, pág. 13.

(C) UNED. Revista de Derecho UNED, núm. 24, 2019 


\section{CONCLUSIONES}

En resumen, se ha citado la normativa promulgada desde los orígenes de la mujer en la milicia, viéndose cómo con el paso del tiempo, se han establecido numerosas medidas para la adaptación y desarrollo de ésta. Como se ha visto después de todo este proceso normativo, se pueden sacar diferentes conclusiones:

- Pese a que la mujer no se incorpora a las FAS hasta el año 1988 , se ha podido comprobar que, en el 1978, tanto en la Constitución Española, como en la Ley 85/1978, de 28 de diciembre, de Reales Ordenanzas de las Fuerzas Armadas, se consagraba el principio de no discriminación por razón de sexo.

- La igualdad entre hombres y mujeres está establecida en las diferentes normativas, tanto internacional, como europea y nacional. En el caso de España, el principio de igualdad y no discriminación se refleja en numerosas leyes.

- Se ha conseguido referenciar una evolución desde una igualdad exclusivamente en el aspecto formal, hasta una igualdad prácticamente real. Se ha visto que las numerosas leyes promulgadas han conseguido, no en su totalidad, alcanzar una igualdad efectiva, que era el objetivo principal establecido en la CE y LOIEMH. Las mejoras en las condiciones de promoción profesional, conciliación familiar, ámbito retributivo, etc. entre hombres y mujeres, han conseguido acercarse a las metas planteadas ${ }^{91}$.

- Uno de los principales problemas que pueden haber repercutido en la mayor o menor rapidez de adaptación de la mujer, se ha encontrado en la conciliación familiar. Aunque no es determinante, sí que influye en aspectos varios como la captación

91 Asimismo, se refleja en la Revista Española de Defensa que concluye que «lo que hace tres décadas era una novedad es hoy una realidad consolidada, en la cual, día tras día, hombres y mujeres conviven y desempeñan sus tareas con total normalidad, bajo un modelo de igualdad legal y efectiva. La integración se ha extendido a todos los puestos y empleos, de manera que actualmente los militares de uno y otro género tienen idénticas tareas, formación, retribuciones y régimen disciplinario» (Vid., F. DEL VADO, S., «30 años de las mujeres en las FAS», Revista española de Defensa, septiembre de 2018, pág. 7). Confirma así una evolución destacando en materia de igualdad, la realidad que se presenta en la actualidad. 
de nuevo personal femenino, así como el seguir sirviendo al país en estas Unidades.

- Aunque queda trabajo por hacer, la igualdad formal y real están muy cerca de equipararse ${ }^{92}$. Hay que seguir profundizando para alcanzar una igualdad plena. Con medidas formales no se va a cambiar los estereotipos. La igualdad formal es condición a la real, pero no es inminente en los resultados.

- Pese al esfuerzo realizado y el total compromiso que se ha tenido a la hora de avanzar en este camino difícil hacia una igualdad plena, se debe seguir trabajando para mejorar las condiciones de esta profesión y así conseguir un incremento de sus efectivos, tanto en hombres, como en mujeres ${ }^{93}$. Al igual que en otras profesiones, en las últimas décadas se ha comprobado la mejoría en materia de igualdad entre $\operatorname{sexos}^{94}$.

\section{Para concluir y en palabras de Lorenzo Cotino:}

"la eficacia militar no atiende a sexos, ni a orientaciones sexuales, pues las cualidades que se requieren en las FAS no guardan relación con la orientación sexual que se tenga, sino lo que debe centrar la atención es la aptitud, vocación y entrega para la vida militar» ${ }^{95}$.

92 "La plena incorporación de las mujeres a las Fuerzas Armadas españolas es una realidad. Asimismo es habitual hablar de "normalidad» e "integración» al hacer referencia a esta incorporación. Incluso el haber tenido una mujer al cargo del Ministerio de Defensa ha adquirido un gran valor simbólico en nuestra sociedad» (Vid., AGUDO ARROYO, Y., "La participación de las mujeres en las Fuerzas Armadas españolas: de la incorporación a la integración», Revista Internacional de Trabajo Social y Ciencias Sociales, 2014, pág. 16).

${ }_{93}$ «Es un porcentaje muy superior al de otros países de Europa, pero, obviamente, deja mucho que desear», advirtió el miércoles 27 de junio de 2018 en el Congreso la ministra de Defensa, Margarita Robles (Diario de Sesiones de las Cortes Generales, XII Legislatura Núm. 547, 2018, pág. 6).

94 "De forma paulatina, al tiempo que iba creciendo el número de mujeres militares, se iban removiendo los obstáculos que dificultaban el acceso a empleos o puestos, al tiempo que se dictaban normas se adaptaban instalaciones, costumbres, procedimientos y vestuarios, hasta dotar a una institución con siglos de tradición de unas condiciones que la han convertido en referente de integración a nivel mundial. En las Fuerzas Armadas españolas no existe ninguna diferenciación por razón de género en formación y destinos, todos sus integrantes cumplen con las mismas tareas específicas, alcanzan los mismos niveles de responsabilidad, se encuentran bajo un único régimen disciplinario y son gratificados mediante el mismo sistema salarial» (Gómez Escarda y Sepúlveda Muñoz, La incorporación de la mujer a las Fuerzas Armadas 2009,62).

${ }_{95}$ Vid. COTINO HUESO, L. El modelo constitucional de Fuerzas Armadas. Valencia, 1999, pág. 470.

(C) UNED. Revista de Derecho UNED, núm. 24, 2019 


\section{BIBLIOGRAFÍA}

Agudo ARRoyo, Y. «La participación de las mujeres en las Fuerzas Armadas españolas: de la incorporación a la integración», Revista Internacional de Trabajo Social y Ciencias Sociales, 2014, págs. 9 a 27.

Alcántara López, R., y Del Pozo Cruz, J.T. «La mujer en las Fuerzas Armadas españolas: la evolución normativa como piedra angular», Investigación y género, logros y retos: III Congreso Universitario nacional. Investigación y género. Sevilla, 2011, págs. 46 a 61.

BERNAL GutIÉRREZ, P. «La cultura de seguridad y defensa en España. Sus orígenes y evolución», Cuadernos de Estrategia, 2011, págs. 23 a 64.

Caballud Hernando, M.B. «Aportación de la mujer militar en las Fuerzas Armadas españolas a la defensa y la seguridad», ARBOR Ciencia, Pensamiento y Cultura, febrero de 2014.

http://arbor.revistas.csic.es/index.php/arbor/article/view/1901/2120 (último acceso: 22 de diciembre de 2018).

Cortes Generales. "Diario de Sesiones del Congreso de los DiPutaDOS» XII LEGISLATURA NÚM. 547, 2018.

Cotino Hueso, L. El modelo constitucional de Fuerzas Armadas. Valencia, 1999.

F. Del VADO, S. «30 años de las mujeres en las FAS», Revista española de Defensa, septiembre de 2018.

FERnández Segado, F. «El nuevo diseño del servicio militar: la Ley Orgánica 13/1991, de 20 de diciembre», Revista de Administración Pública $n^{\circ} 129,1992$, págs. 77 a 116.

Foro de Cultura De Defensa. «Las DAMAS del Ejército: Sanidad Militar (I)» 17 de abril de 2013. http://forodeculturadedefensa.blogspot.com/2013/04/las-damas-del-ejercito-sanidad-militar-i.html (último acceso: 6 de diciembre de 2018).

Fraiz Padín, M.A., M.M. Martínez Fernández, M.J. Moreno CorraLES, y M.J. Fraiz PAdín. «Las otras enfermeras, durante la Guerra Civil Española», 2015.

https://www.researchgate.net/publication/292983004_PARANINFO_DIGITAL_Las_otras_enfermeras_durante_la_Guerra_Civil_Espanola (último acceso: 8 de 12 de 2018).

Gallardo Rodríguez, P. «La mujer militar en las Fuerzas Armadas» en El papel de la mujer y el género en los conflictos. Cuadernos de 
Estrategia $n^{\circ} 157$, págs. 139 a 174 . Granada: Instituto español de Estudios Estratégicos, 2012.

GARCía SÁNCHEZ, B. «Integración real e instrumentalización de la imagen de la mujer en las Fuerzas Armadas españolas» Journal of feminist, gender and women studies, 2016, págs. 21 a 28.

GonzÁlez Yanes, J. Historia de la enfermería en la Defensa. Ejército de Tierra: regulación normativa y marco jurídico de funciones profesionales. Tenerife, 2014.

LóPez De Gea, J. «Derechos Fundamentales y Estatuto Jurídico de las Fuerzas Armadas», Madrid, 2013.

Martín Martínez, V. «La incorporación de la mujer a las Fuerzas Armadas» en Las mujeres militares en España (1988-2008), de GóMEZ Escarda, M. y SePúlveda MuÑoz, I., págs. 23 a 44. Madrid: Instituto Universitario General Gutiérrez Mellado, 2009.

Ministerio DE DefEnsa. Observatorio militar para la Igualdad entre mujeres y hombres en las Fuerzas Armadas, 2018.

http://www.defensa.gob.es/ministerio/organigrama/subdef/omi/ (último acceso: 25 de diciembre de 2018).

Moreno Martínez, C. Mujeres policía, mujeres militares, especial referencia a la mujer Guardia Civil, Madrid, 1998.

Navarro Carballo, J.R. "Creación y desarrollo del Cuerpo de Damas Auxiliares de Sanidad Militar», Revista de Sanidad de las Fuerzas Armadas de España Vol. 43 n. ${ }^{\circ 3}$, 1987, págs. 320 a 331.

Pomed Sánchez, L.A. «Objeción, Insumisión y Servicio militar obligatorio", Revista de Administración Pública n. ${ }^{\circ}$ 134, 1994, págs. 155 a 222 .

Quesada GonzÁlez, J.M. "Las señoritas de la Cruz de Malta: una visión objetiva sobre las Damas Auxiliares de Sanidad Militar», Revista de historia militar $.^{\circ} 119,2016$, págs. 217 a 244. 